\title{
TANK-binding kinase 1 mediates phosphorylation of insulin receptor at serine residue 994: a potential link between inflammation and insulin resistance
}

\author{
Marina C Muñoz ${ }^{1}$, Jorge F Giani ${ }^{1}$, Marcos A Mayer ${ }^{2}$, Jorge E Toblli ${ }^{3}$, Daniel Turyn ${ }^{1}$ \\ and Fernando $\mathbf{P}$ Dominici ${ }^{1}$ \\ ${ }^{1}$ Instituto de Química y Fisicoquímica Biológicas (UBA-CONICET), IQUIFIB and ${ }^{2}$ Cátedra de Farmacología, Facultad de Farmacia y Bioquímica, Universidad de \\ Buenos Aires, Junín 956, Capital Federal, 1113 Buenos Aires, Argentina \\ ${ }^{3}$ Laboratorio de Medicina Experimental, Hospital Alemán, Avenue Pueyrredón 1640, 1118 Buenos Aires, Argentina \\ (Correspondence should be addressed to F P Dominici; Email: dominici@gb.ffyb.uba.ar)
}

\begin{abstract}
The I $\mathrm{KB}$ kinase- $\beta$ (IKK- $\beta$ )/nuclear factor- $\kappa \mathrm{B}$ signaling pathway has been suggested to link inflammation with obesity and insulin resistance. In addition, angiotensin (Ang) II is able to induce insulin resistance and an inflammatory state through Ang II receptor type 1 (AT1R). Accordingly, we examined whether inhibition of AT1R with irbesartan (IRB) can protect against the development of insulin resistance in obese Zucker rats (OZRs). IRB-treatment improved the insulin-stimulated insulin receptor (IR) phosphorylation at tyrosine (Tyr) residues 1158, 1162, 1163 (involved in activation of the IR kinase) and at Tyr972 (involved in substrate recognition). AT1R blockade also originated a dramatic increase in the phosphorylation of Akt and glycogen synthase kinase- $3 \beta$. This was accompanied by a decrease in
\end{abstract}

phosphorylation of IR on serine (Ser) 994, a residue that seems to be implicated in the regulation of IR kinase in OZR. In this study, we demonstrated that Ser994 of IR is a direct substrate for TANK-binding kinase 1 (TBK1), a new member of the IKK-related kinase family. TBK1 was found to co-immunoprecipitate with the IR, in the liver of OZR supporting an in vivo association between the IR and TBK1. Interestingly, a marked increase in the association between TBK1 and the IR was found in the liver of OZR as well as in other models of insulin resistance/diabetes. Taken together, these findings suggest that TBK1 could be involved in the insulin resistance mechanism related with IR Ser994 phosphorylation in a genetic model of diabetes.

Journal of Endocrinology (2009) 201, 185-197

\section{Introduction}

The insulin receptor (IR) is a tetrameric protein composed of two extracellular $\alpha$-subunits that bind insulin linked by disulfide bonds to two transmembrane $\beta$-subunits that have intracellular tyrosine kinase activity (White \& Kahn 1994). In particular, the phosphorylation of three tyrosine (Tyr) residues $(1158,1162$, and 1163) in the kinase domain results in maximum tyrosine kinase activity and enable the subsequent phosphorylation of several endogenous proteins including the IR substrates family of proteins (IRS- 1 to -4 ; White \& Kahn 1994, Youngren 2007). Phosphorylation of the IR at Tyr972 serves as a binding site for the phosphotyrosine-binding domains of IRS- 1 facilitating the subsequent phosphorylation of this substrate on numerous Tyr sites. These events are essential for further signal transduction and consequently for insulin action (Youngren 2007). In addition to Tyr, the IR undergoes serine (Ser) and threonine (Thr) phosphorylation, which is detected both in the basal state and in response to stimulation of cells by phorbol esters (Bollag et al. 1986,
Takayama et al. 1988), cAMP analogues (Stadtmauer \& Rosen 1986), and insulin itself (Kasuga et al. 1982, Häring et al. 1984, Pillay et al. 1991). Ser/Thr phosphorylation of the IR may also participate in the regulation of insulin signaling and action in vivo. In fact, impaired activation of IR associated with excessive Ser/Thr phosphorylation has been reported in animal models of insulin resistance as well as in certain types of insulin-resistant states in humans (Li et al. 2002, Johnston et al. 2003, Taniguchi et al. 2006, Youngren 2007). IR Ser994 is one of the potential inhibitory sites of the IR kinase as determined by site-directed mutagenesis (Strack et al. 1997, 2000). In previous works, we demonstrated that phosphorylation at this site was increased in IR isolated from the liver of obese Zucker rats (OZRs; Coba et al. 2003, Muñoz et al. 2006). Among the serine kinases implicated in Ser phosphorylation of the IR and the IRSs, protein kinase C (PKC) is one candidate with potential pathophysiological relevance. Numerous studies have linked excessive PKC activity to diminished insulin sensitivity, especially to that occurring together with increased lipid availability 
(Considine et al. 1995, Qu et al. 1999, Itani et al. 2000). We have previously reported that IR Ser994 is an in vitro phosphorylation target for PKC (Coba et al. 2003). However, the participation of additional serine kinases cannot be ruled out.

Obesity and insulin resistance are closely associated with a state of chronic low-grade inflammation characterized by abnormal cytokine production and macrophage infiltration into adipose tissue (Shoelson et al. 2006). Circulating levels of adipose-secreted cytokines with the ability of inhibiting insulin action such as tumor necrosis factor (TNF- $\alpha$ ) and interleukin-6 (IL-6) are increased in obese subjects and rodents (Pickup \& Crook 1998, Kern et al. 2001, Pradhan et al. 2001). Furthermore, locally produced cytokines have been shown to impair insulin action in the livers of several insulin resistant rodent models (Arkan et al. 2005). TNF- $\alpha$ activates the inflammation pathway that includes the inhibitor $\beta$-kinase complex and it downstream efector

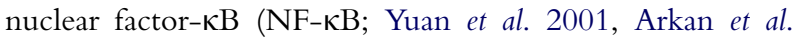
2005, Cai et al. 2005).

The renin-angiotensin (Ang) system is an additional link between inflammation and insulin resistance. The main player in this connection is Ang II acting through the AT1R (Velloso et al. 2006, Folli et al. 1997, Jandeleit-Dahm et al. 2005). This correlates well with the beneficial effect of Ang II receptor type 1 (AT1R) blockers (e.g. irbesartan, IRB), on insulin sensitivity (Henriksen et al. 2001, Shiuchi et al. 2004, Muñoz et al. 2006). In a previous study, we demonstrated that blockade of the AT1R with IRB leads to an improvement of the response to insulin at the early stages of the insulin signaling pathway in the liver of OZRs which correlates with a reduction of the phosphorylation of the IR at Ser994 (Muñoz et al. 2006).

TANK-binding kinase 1 (TBK1), a new member of the (I $\mathrm{B}$ kinase, IKK)-related kinase family, participates in inflammatory pathways related to activation of $N F-\kappa B$ (Pomerantz \& Baltimore 1999). In the present study, we sought to determine the participation of TBK1 in the in vivo phosphorylation of the IR at Ser994 and its consequences on the modulation of insulin signaling. Accordingly, we have measured the in vivo phosphorylation levels of the Tyr residues $1158 / 1162 / 1163,972$, and Ser994 of the IR in the livers of control animals, OZR, and OZR that were treated for 6 months with IRB. Activation levels of Akt and glycogen synthase kinase-3 $\beta$ (GSK-3 $\beta$ ) were measured as a parameter of insulin sensitivity in the liver. We measured liver expression of TNF- $\alpha$ in the three groups of animals. In addition, we determined the activity and protein levels of TBK1 and explored the interaction between this kinase and the IR. These results were corroborated by measuring the interaction between the IR and TBK1 in various models of insulin resistance including the ob/ob mouse, the agouti obese yellow mouse and the Zucker diabetic fatty (ZDF) rat. The participation of TNF- $\alpha$ as an inductor of TBK-1 in TNF- $\alpha$ treated rats.

\section{Materials and Methods}

\section{Animal models and surgery}

All the experiments were approved by the Hospital Alemán Ethic Committee and the Teaching and Research Committee and followed the National Institute of Health Guide for the Care and Use of Laboratory Animals. All the animals were given free access to water, and standard rat chow (16-18\% protein, Cargill, Buenos Aires, Argentina).

Study 1 Effects of IRB treatment on insulin signaling in the liver of OZRs. Ten-week old male OZRs ( $f a / f a$; OZR) and their age-matched lean controls ( $+/$ ?; lean Zucker rats (LZR); Charles River Laboratories, Wilmington, MA, USA) were housed in individual cages at $21 \pm 2{ }^{\circ} \mathrm{C}$ on a $12 \mathrm{~h}$ light:12 h darkness cycle (0700-1900 h), and divided into three groups $(n=8)$ : OZR Group; OZR treated with IRB Group; and LZR Group. In order to obtain blood pressure control, the dose of IRB was chosen according to previous studies (Dohi et al. 1994, O’Donnell et al. 1997, Henriksen et al. 2001). During 6 months, all the animals were treated according to the following schedule: OZR and LZR group no treatment; OZR + IRB group received IRB $(50 \mathrm{mg} / \mathrm{kg}$ per day). IRB was administered daily between 1100 and $1200 \mathrm{~h}$ by gavage. Dose treatment was adjusted each week based on the calculation of the body weight for each animal. At the end of the 6 month treatment, rats were fasted overnight $(12 \mathrm{~h})$ and were anesthetized with sodium thiopental $40 \mathrm{mg} / \mathrm{kg}$, i.p., (Baxter Pharmaceutical Products, Deerfield, IL, USA). After anesthesia was induced, the portal vein was exposed and $10 \mathrm{IU}$ porcine insulin per $\mathrm{kg}$ of body weight in normal saline $(0.9 \% \mathrm{NaCl})$ in a final volume of $0.1 \mathrm{ml}$ was injected via this vein as described previously (Muñoz et al. 2006). To obtain data under basal conditions, animals were injected with diluent. Approximately $1 \mathrm{~min}$ after injection, the liver was removed and kept at $-80{ }^{\circ} \mathrm{C}$ until analysis.

Study 2 Degree of phosphorylation of the IR at Ser994, hepatic TBK1 protein levels and association between TBK1 and the IR in animal models of insulin resistance and/or diabetes. Six to seven-month old male mice of the genetically obese/diabetic models ob/ob (C57BL/6J-ob/ob) and agouti

Table 1 Study 1: metabolic parameters of the experimental animals

\begin{tabular}{|c|c|c|c|}
\hline & OZR & $\begin{array}{l}\text { OZR } \\
\text { with IRB }\end{array}$ & LZR \\
\hline Body weight (g) & $626 \pm 21^{*}$ & $600 \pm 20^{\ddagger}$ & $381 \pm 3$ \\
\hline $\mathrm{SBP}(\mathrm{mmHg})$ & $153 \pm 2^{*,+}$ & $129 \pm 1$ & $120 \pm 1$ \\
\hline Serum glucose $(\mathrm{mg} / \mathrm{dl})$ & $200 \pm 2 *$ & $185 \pm 4^{\neq}$ & $99 \pm 4$ \\
\hline Serum insulin $(\mathrm{ng} / \mathrm{ml})$ & $4 \cdot 5 \pm 0 \cdot 3^{*,+}$ & $2 \cdot 40 \pm 0 \cdot 05^{\neq}$ & $0 \cdot 30 \pm 0 \cdot 02$ \\
\hline Triglycerides (mg/dl) & $1058 \pm 53^{*,+}$ & $543 \pm 26^{\neq}$ & $23 \pm 4$ \\
\hline
\end{tabular}

SBP, systolic blood pressure; IRB, irbesartan. Values are means \pm S.E.M. $(n=8$ in all cases). ${ }^{*} P<0 \cdot 01$ versus $L Z R ;{ }^{+} P<0 \cdot 01$ versus $\mathrm{OZR}+\mathrm{IRB} ;{ }^{\ddagger} P<0 \cdot 01$ versus $\mathrm{LZR}$. 
A

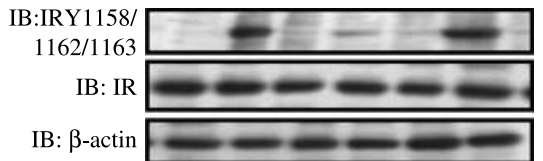

IB: $\beta$-actin $=-\infty$

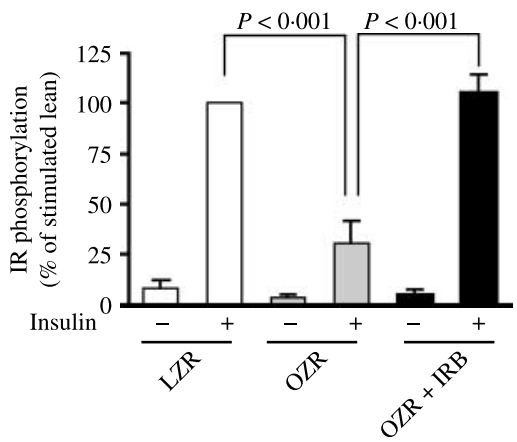

B
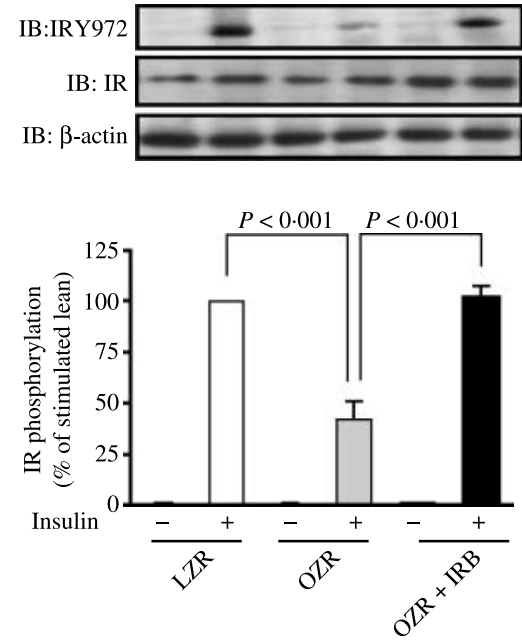

Figure 1 Hepatic phosphorylation of IR Tyr1158/Tyr1162/Tyr1163 in lean Zucker rats (LZR), obese Zucker rats (OZR) and irbesartan-treated obese Zucker rats (OZR+IRB) (A). IR Tyr972 phosphorylation (B). The immunoblots shown are representative of four blots for each panel $(n=4)$.

(C57BL/6J-A) and their wild-type controls C57BL/6J a/a were purchased from The Jackson Laboratory (Bar Harbor, ME, USA). Six to eight-month old male ZDF/Gmi-fa/fa and their heterozygous ( $\mathrm{ZDF} / \mathrm{Gmi}-+/ \mathrm{fa}$ ) lean littermates were purchased from Charles River Laboratories. After a $12 \mathrm{~h}$ fast, animals were killed and liver and plasma were collected. For TNF- $\alpha$ treatment, 7-month old male LZR ( + /?; LZR) from Charles River laboratories were used. Rats were anesthetized with a mixture of chloralose $(50 \mathrm{mg} / \mathrm{kg}$ body weight) and urethane $(500 \mathrm{mg} / \mathrm{kg}$ body weight) and had polyethylene cannulas surgically implanted into the femoral vein for continuous TNF- $\alpha$ infusion. TNF- $\alpha$ (human recombinant, Sigma-Aldrich) was dissolved in saline and $0 \cdot 1 \%$ BSA). A tracheotomy tube was inserted, and the animal was allowed to spontaneously breathe room air throughout the course of the experiment. Body temperature was maintained using a
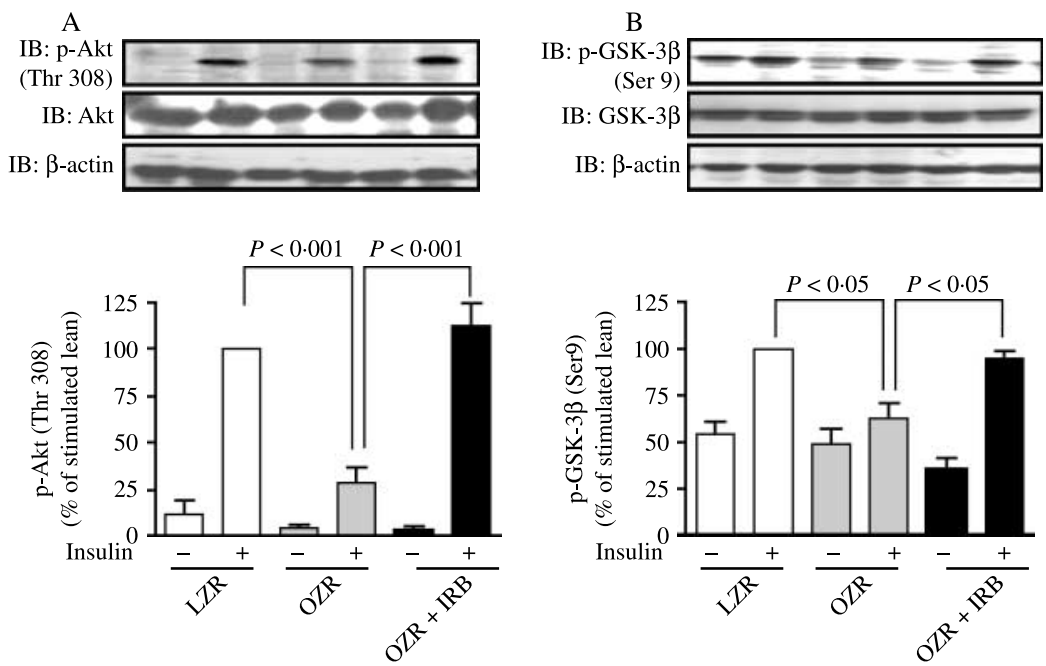

Figure 2 Akt phosphorylation (A). GSK-3 $\beta$ phosphorylation at Ser9. Each bar represents the mean \pm S.E.M. of four experiments. To determine the protein levels of Akt and GSK-3 $\beta$, membranes were stripped and reprobed with anti-Akt or GSK-3 $\beta$ antibody (middle panels) (B). Equal protein loading in the gels was confirmed by reblotting the membranes with an anti- $\beta$ actin antibody ( $\mathrm{A}$ and $\mathrm{B}$; bottom panels). 


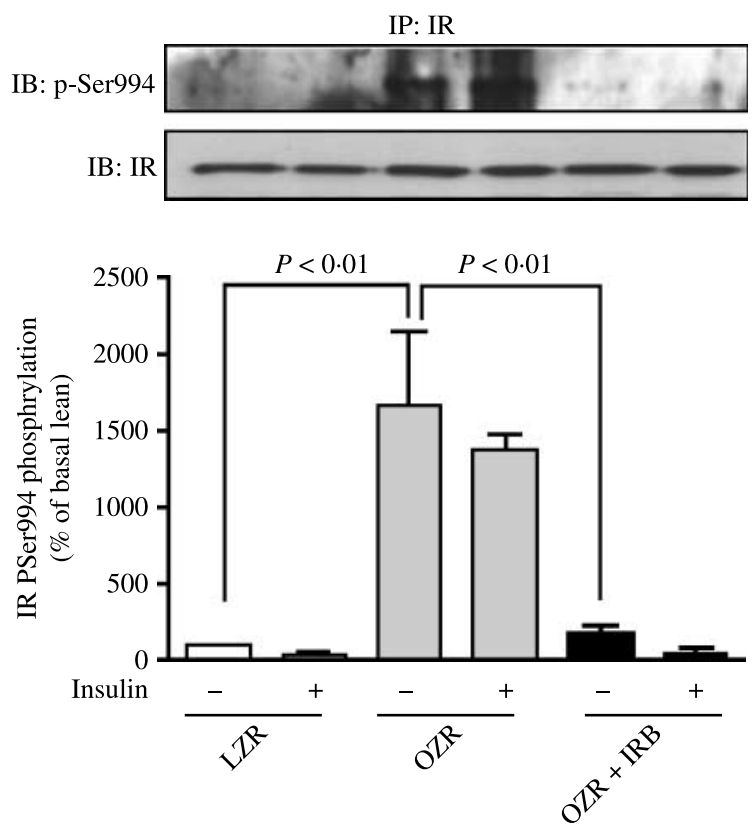

Figure 3 Phosphorylation status of the IR at Ser994 in liver. Serine representative blots are shown. Values are the mean \pm S.E.M. of four separate experiments expressed as relative to saline-injected LZR values that were set as $100 \%(n=4)$.

heating lamp positioned above the rat. Once the surgery was completed, rats were infused with saline or TNF- $\alpha(1 \mu \mathrm{g} / \mathrm{kg}$ per $\mathrm{h}$ for $4 \mathrm{~h}$ ) using a standard infusion pump. This protocol was chosen according to a previous study (Qin et al. 2008). At the end of the study, rats were killed and the liver was excised for western blotting analysis.
Insulin, glucose, and triglyceride concentration measurement

All determinations were done after $12 \mathrm{~h}$ fasting. Insulin levels were assessed using a rat insulin ELISA kit (Ultra Sensitive Rat Insulin ELISA Kit; Crystal Chem Inc., Downers Grove, Illinois, USA). Serum glucose was measured with the glucose oxidase procedure (Trender; Sigma Chemical Co). Serum triglycerides (TGs) were assessed according to standard methods. Total coefficient of variation of the assay was $4 \%$.

\section{Materials}

The reagents and apparatus for SDS-PAGE and immunoblotting were obtained from Bio-Rad. The anti- $\beta$-actin antibody (A 2266), TNF- $\alpha$, STZ, and remaining reagents were purchased from Sigma-Aldrich Corp. The polyclonal anti-phospho-IR (Tyr972) antibody (07-838), the polyclonal anti-phospho-IR (Tyr1158/Tyr1162/Tyr1163; 07-841), the polyclonal anti-phospho-Akt (Thr308; 06-678), TBK1, active enzyme (14-628) and the peptide CK1tide (12-529; KRRRALS(p)VASLPGL; positive control were purchased from Upstate Biotechnology, Millipore (Lake Placid, NY, USA). The polyclonal anti-IR $\beta$-subunit antibody (sc-711), goat anti-rabbit $\operatorname{IgG}$ conjugated with horse radish peroxidase (HRP; sc-2004), goat anti-mouse IgG-HRP (sc-2005) and donkey anti-goat IgG-HRP (sc-2020) secondary antibodies were purchased from Santa Cruz Biotechnology, Inc. (Santa Cruz, CA, USA). Akt polyclonal antibody and TBK1/NAK polyclonal antibody (3013) were purchased from Cell Signaling (Beverly, MA, USA). Antibody against rat TNF- $\alpha$ (AF-510NA) was acquired from R\&D Systems, Minneapolis, MN, USA. The polyclonal antibody against phospho-Ser994 of the IR (anti-p-S994) was obtained by immunization of rabbits
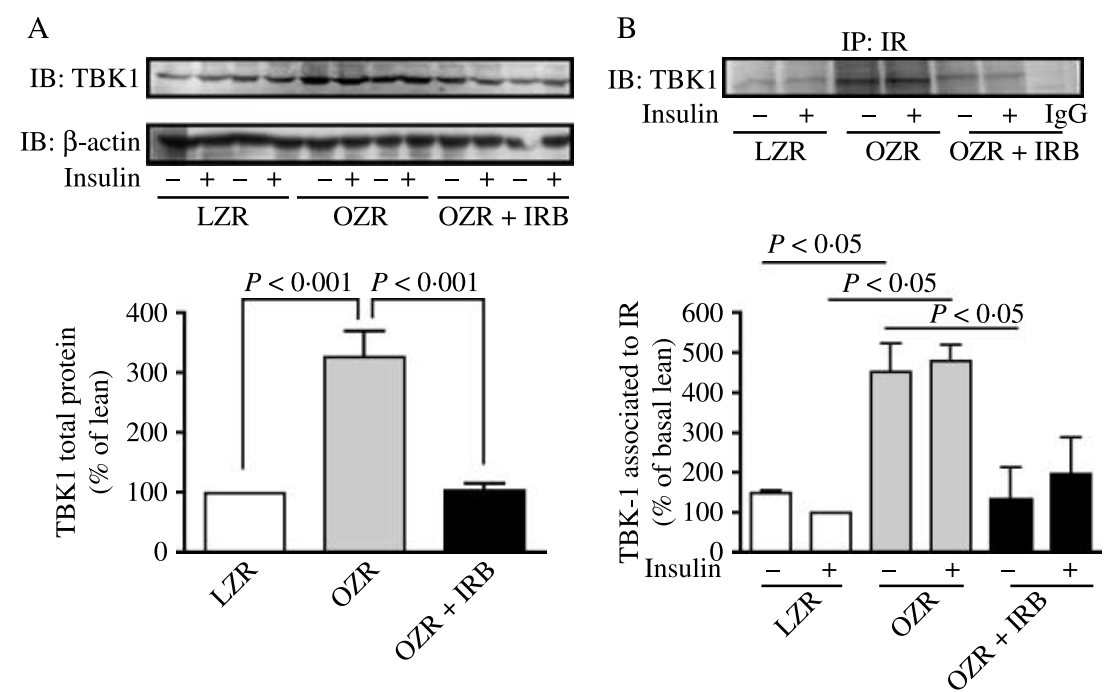

Figure 4 TBK1 protein levels in liver. Values are means \pm S.E.M. and are presented as a percentage of LZR $(n=8)(\mathrm{A})$. TBK1 interaction with the IR $(\bar{B})$. Values are means \pm S.E.M. and are presented as a percentage of saline-injected LZR $(n=3)$. 


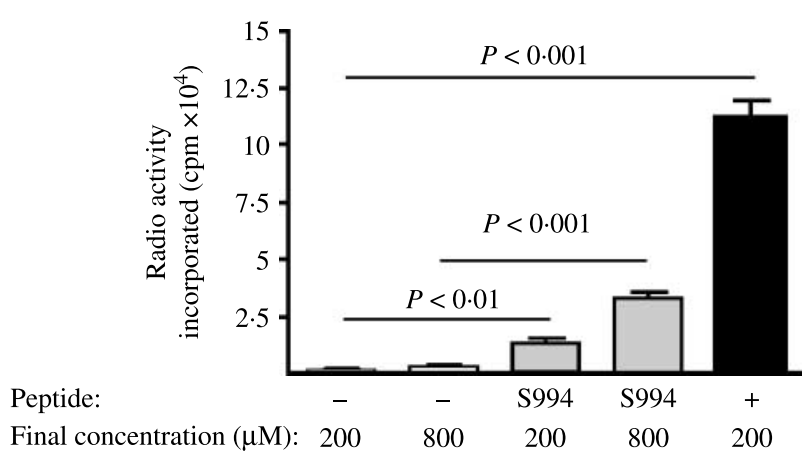

Figure 5 In vitro phosphorylation of a peptide corresponding to a fragment of the IR that includes phosphorylation site Ser994 by TBK1. The kinase assay was carried out in the presence of three different peptides: a negative control $(-)$ : LRELGQGAFGMVYEG, IR Ser994: LRELGQGSFGMVYEG or a positive control $(+)$ : KRRRALPSVASLPGL that were added to the reaction buffer at the indicated concentrations. Bars represent the means \pm S.E.M. of the radioactivity incorporated in each condition that was analyzed in triplicate. Data shown are representatives of three independent experiments.

with the phopsphorylated peptide LRELGQGpSFGMVYE, as previously described (Coba et al. 2003). Peptides were purchased from GenScript Corporation (Piscataway, NJ, USA).

\section{Tissue homogenization}

Tissue samples were coarsely minced, and homogenized in 10 volumes of solubilization buffer A (1\% Triton, $100 \mathrm{mM}$ Tris (pH 7·4), $100 \mathrm{mM}$ sodium pyrophosphate, $100 \mathrm{mM}$ sodium fluoride, $10 \mathrm{mM}$ EDTA, $10 \mathrm{mM}$ sodium vanadate, $2 \mathrm{mM}$ phenylmethylsulphonyl fluoride, and $0.1 \mathrm{mg} / \mathrm{ml}$ aprotinin) at $4{ }^{\circ} \mathrm{C}$ as described previously (Coba et al. 2004). Liver extracts were centrifuged at $100000 \mathrm{~g}$ for $1 \mathrm{~h}$ at $4{ }^{\circ} \mathrm{C}$ to eliminate insoluble material, and protein concentration in the supernatants was measured using the Bradford method as described previously (Coba et al. 2004).

\section{Immunoprecipitation and immunoblotting}

Equal amounts of solubilized liver protein were incubated at $4{ }^{\circ} \mathrm{C}$ overnight with anti-IR at a final concentration of $4 \mu \mathrm{g} / \mathrm{ml}$. Immune complexes were collected by incubation with protein A-Sepharose $6 \mathrm{MB}$ as described previously (Coba et al. 2004). SDS-PAGE and western transfer of proteins to PVDF membranes (Hybond-P, GE Healthcare Bio-Sciences, Piscataway, NJ, USA) were performed as previously described (Coba et al. 2004). Membranes were blocked by incubation for $2 \mathrm{~h}$ with a blocking buffer composed of Tris-bufferedsaline-Tween 20 (TBS-T) buffer (10 mM Tris- $\mathrm{HCl}$ ( $\mathrm{pH} 7 \cdot 6$ ), $150 \mathrm{mM} \mathrm{NaCl}$, and $0 \cdot 02 \%$ Tween 20 ) containing 3\% BSA. The membranes were then incubated overnight with antip-S994 (1:200 dilution) or anti-TBK1 (1:2000 dilution). To determine IR protein abundance membranes were reblotted with anti-IR (1:2000). To determine the phosphorylation levels of IR and Akt and the total protein abundance of TNF- $\alpha$, equal amounts of solubilized proteins $(20-40 \mu \mathrm{g})$ were denatured by boiling in reducing sample buffer, resolved by SDS-PAGE, and subjected to immunoblotting with either anti-phospho-Akt (1:5000), anti-phospho-IR (1:5000) or anti-TNF- $\alpha$ (1:1000). Hepatic Akt and IR abundance were detected by reprobing the corresponding membranes with the anti-Akt (1:1000) or anti-IR (1:2000) antibodies. To determine whether TBK1 interacts with the IR in vivo, we performed a co-immnunoprecipitation experiment. IR was immunoprecipitated using anti-IR $\beta$-subunit antibody $(4 \mu \mathrm{g} / \mathrm{ml})$ from liver protein extracts and then SDSPAGE and western transfer of proteins to PVDF membranes was performed. The membranes were then incubated overnight with anti-TBK1 antibody (1:2000). After extensive washing, membranes were incubated with the appropriate secondary HRP-coupled antibodies for $1 \mathrm{~h}$. Phosphorylated proteins were visualized on Kodak X-Omat AR film (Kodak) using an enhanced chemiluminescence detection system (GE Healthcare Bio-Sciences). Band intensities on the autoradiographs were quantified using an image densitometer (Gel-Pro Analyzer 4.0, Media Cybernetics, Inc., Bethesda, MD, USA). Protein loading in gels was evaluated by stripping and reblotting membranes with antibodies to unphosphorylated proteins. Protein loading in gels was evaluated by reblotting membranes with anti- $\beta$-actin antibody $(1: 5000)$.

\section{Measurement of TBK1 activity in vitro}

TBK1 kinase activity was measured using in vitro assay. TBK1 enzyme was purchased from Upstate Biotechnology, Millipore. The assay was performed according to manufacturer's instructions. In a preliminary experiment, the optimal concentration of TBK1 to be used in the assay was determined by using a positive peptide recommended by the manufacturer. For the in vitro kinase assay, $2.5 \mu \mathrm{l}$ of each substrate peptide $(200 \mu \mathrm{M}$ final concentration); negative control: LRELGQGAFGMVYEG; positive control: KRRRALpSVASLPGL or IR Ser994: LRELGQGSFGMVYEG were added to the reaction buffer. Then, $2 \cdot 5 \mu \mathrm{l}$ TBK1 active $(25 \mathrm{ng})$ were added and finally $10 \mu \mathrm{l}\left[\gamma_{-}{ }^{32} \mathrm{P}\right]$ ATP $(10 \mu \mathrm{Ci} ; 100 \mu \mathrm{M}$ final concentration) was added. The reaction was incubated for $30 \mathrm{~min}$ at $30{ }^{\circ} \mathrm{C}$ with agitation and terminated by transference of an aliquot of $20 \mu$ lonto the center of a numbered P81 paper square, which was then washed three times with $0.75 \%$ phosphoric acid and once with acetone. The squares were transferred to a scintillation vial with $4 \mathrm{ml}$ scintillation cocktail and the level of radioactivity was determined in a scintillation counter. The activity of each sample was corrected by the activity of the control sample with no enzyme (background control). A sample that contained no substrate peptide was also included as a negative control. The values obtained for both controls were similar. 


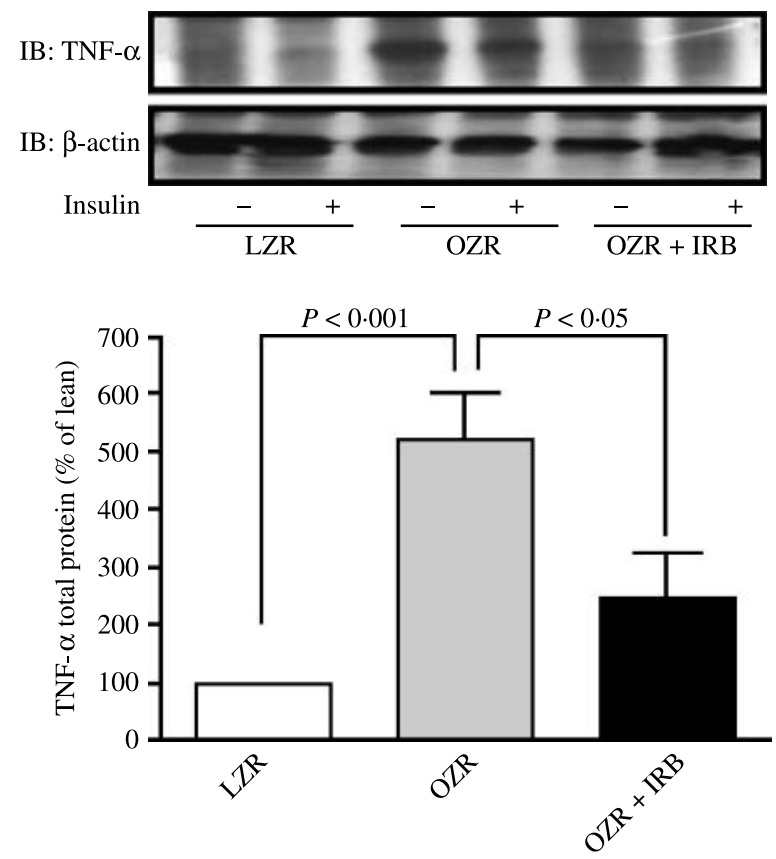

Figure 6 Hepatic TNF- $\alpha$ protein expression. Values are means \pm S.E.M. and are expressed as relative to LZR values that were set as $100 \%$.

\section{Statistical analysis}

Results are presented as means \pm S.E.M. unless otherwise indicated. Experiments were performed by analyzing all groups of animals in parallel. Data were analyzed with ANOVA followed by the Tukey-Kramer test using GraphPad version 4.00 by GraphPad Software, Inc. (San Diego, CA, USA). The level of significance was set at $P<0 \cdot 05$.

\section{Results}

\section{Study 1}

Animal characteristics As shown in Table 1, OZR had elevated glucose levels, were markedly hyperinsulinemic, and presented a dramatic increase in the circulating concentration of TGs. IRB was effective in reducing both insulin and TG levels but did not modify glucose levels. Despite the large reduction in both insulin and TG levels, OZR treated with IRB still presented hyperinsulinemia and hypertriglyceridemia when compared with LZR.

\section{Degree of phosphorylation of the IR at residues in} the kinase domain (Tyr1158/1162/1163), IRS-1 binding domaing (Tyr972) For comparison and evaluation, the value of insulin-stimulated LZR was set as $100 \%$. Basal IR tyrosine phosphorylation values were very low in all four groups of animals (Fig. 1A and B). Acute in vivo insulin administration induced a 12-fold increase in the Tyr1158/1162/1163 phosphorylation of the IR in the liver of normal animals (Fig. 1A), while the same stimulus induced a sevenfold increase in the phosphorylation of the IR in OZRs (Fig. 1A). The IR response to in vivo insulin administration was restored by IRB treatment (Fig. 1A). Similar results were observed when IR Tyr972 phosphorylation was measured (Fig. 1B). As shown in Fig. 1A and B (middle panels), IR abundance was similar in all groups. Total amount of protein loaded in the gels was controlled by reprobing the same membranes with anti- $\beta$ actin (Fig. 1, lower panels).

Phosphorylation state of Akt and GSK-3 $\beta$ As shown in Fig. 2A, phosphorylation of Akt at Thr308 increased after in vivo insulin administration. The level of phosphorylation of Akt after insulin stimulation was decreased by $73 \%$ in OZR $(P<0 \cdot 001)$ compared with values measured in LZR (Fig. 2A). IRB treatment restored the insulin-induced activation of Akt in the liver of OZR. Quantitation of multiple experiments revealed that the protein content of Akt in the liver was similar in the three groups of animals (Fig. 2A). To evaluate one of the effector proteins of insulin metabolic action, the phosphorylation of GSK-3 $\beta$ was determined by subjecting liver extracts to immunobloting with anti-phospho-GSK-3 $\beta$. Phosphorylation of GSK- $3 \beta$ was decreased by $36 \%$ in OZR $(P<0 \cdot 05$; Fig. 2B). This alteration was abolished after long-term treatment with IRB (Fig. 2B). The three groups of animals displayed a similar abundance of Akt and GSK-3 $\beta$ in liver (Fig. 2A and B, middle panels). Total amount of protein loaded in the gels was controlled by reprobing the same membranes with anti- $\beta$ actin (Fig. 2 , lower panels).

Table 2 Study 2: metabolic parameters of the experimental animals

\begin{tabular}{|c|c|c|c|c|}
\hline$n$ & Weight $(\mathrm{g})$ & $\begin{array}{l}\text { Serum glucose } \\
(\mathrm{mg} / \mathrm{dl})\end{array}$ & $\begin{array}{l}\text { Serum insulin } \\
(\mathrm{ng} / \mathrm{ml})\end{array}$ & $\begin{array}{l}\text { Serum trigly } \\
(\mathrm{mg} / \mathrm{dl})\end{array}$ \\
\hline 3 & $32 \pm 2$ & $140 \pm 15$ & $0.43 \pm 0.08$ & $44 \pm 2$ \\
\hline 3 & $67 \pm 5^{*}$ & $280 \pm 28^{*}$ & $6 \cdot 8 \pm 0.9 *$ & $65 \pm 5^{+}$ \\
\hline 7 & $33 \pm 1$ & $144 \pm 18$ & $0 \cdot 8 \pm 0 \cdot 2$ & $50 \pm 6$ \\
\hline 7 & $46 \pm 3^{*}$ & $269 \pm 30^{*}$ & $2 \cdot 0 \pm 0 \cdot 3 *$ & $61 \pm 12$ \\
\hline 5 & $295 \pm 20$ & $113 \pm 15$ & $2 \cdot 8 \pm 0 \cdot 5$ & $34 \pm 15$ \\
\hline 6 & $442 \pm 13^{*}$ & $506 \pm 112^{*}$ & $4 \cdot 1 \pm 0 \cdot 8$ & $656 \pm 166^{*}$ \\
\hline
\end{tabular}

Values represent the means \pm S.E.M. of $n$ animals. Statistical comparison: $* P<0 \cdot 01 ;{ }^{\dagger} P<0 \cdot 05$ versus control group. 

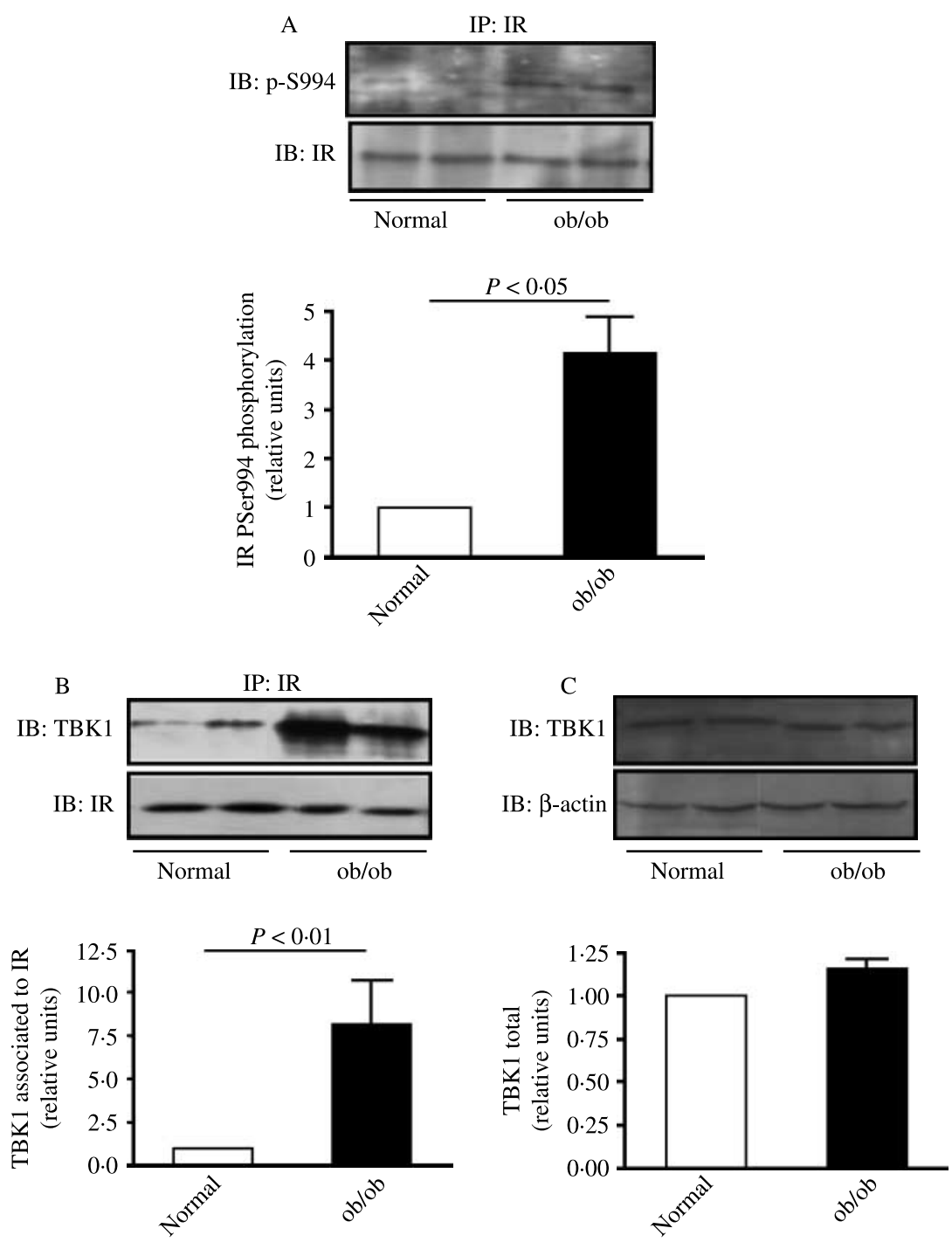

Figure 7 Degree of phosphorylation of the IR at Ser994 in liver of ob/ob mice (A). Association between the IR and TBK1 (B). Hepatic TBK1 protein levels (C). Quantification of phosphorylation by scanning densitometry is given below immunoblots. Scanning data are expressed as fold increase over control values \pm S.E.M. $(n=3)$.

\section{Degree of phosphorylation of the IR at Ser994}

In accordance with our previous reports (Coba et al. 2003, Muñoz et al. 2006), IR Ser994 phosphorylation was almost undetectable in the liver of LZR (Fig. 3). By contrast, basal phospho-Ser994 levels were increased by $\sim 36$-fold in IRs isolated from liver of OZR $(P<0 \cdot 01$ versus saline-injected LZR; Fig. 3). After the administration of IRB obese rats displayed an extremely low level of IR Ser994 under basal conditions, when compared with OZRs $(P<0 \cdot 01$; Fig. 3). When compared with the respective basal values, insulin stimulation did not significantly alter the p-S994 levels of the IR in any of the analyzed groups of animals. Hepatic IR abundance was similar in all groups of animals (Fig. 3, lower panel).
Hepatic TBK1 protein levels and association between TBK1 and the IR When compared with lean animals, the level of total TBK1 protein in OZR was 3.3-fold higher $(P<0 \cdot 001)$. As shown in Fig. $4 \mathrm{~A}$, chronic treatment with IRB led to a significant reduction in the hepatic amount of TBK1, reaching values that were undistinguishable from those found in liver of LZR. The total amount of protein loaded in the gels was controlled by reprobing the same membranes with anti- $\beta$ actin (Fig. 4A). TBK1 was found to co-immunoprecipitate with the IR in all groups of animals (Fig. 4B). Compared with lean animals, OZR exhibited a robust and significant increase in the association of IR with TBK1 that was independent of insulin stimulation (fivefold 


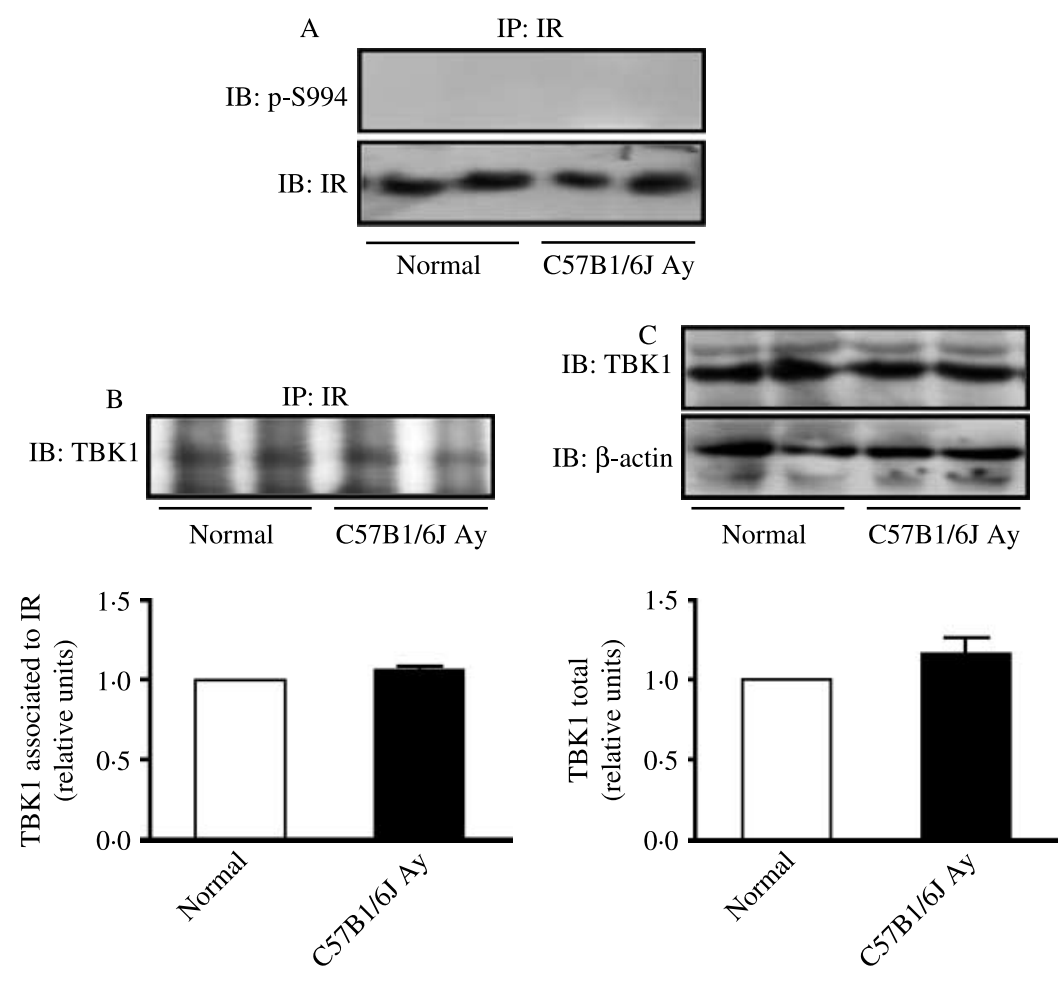

IP: IR

Figure 8 Degree of phosphorylation of the IR at Ser994 in liver of obese yellow mice (A). Association between the IR and TBK1 (B). Hepatic TBK1 protein levels (C). Quantification of phosphorylation by scanning densitometry is given below immunoblots. Scanning data are expressed as fold increase over control values \pm S.E.M. $(n=7)$.

increase; $P<0 \cdot 05$; Fig. 4B). The elevated association between IR and TBK1 in the liver of OZR could be the result of the elevated amount of TBK1 total protein. Treatment with IRB reduced TBK1 binding to the IR to lean values (Fig. 4B).

Phosphorylation of Ser994 by TBK1 In an in vitro kinase assay, we demonstrated that TBK1 is able to phosphorylate a peptide of 15 residues corresponding to a sequence of the IR that includes Ser994 (Fig. 5). Phosphorylation was detected at the two concentrations used $(200$ and $800 \mu \mathrm{m})$. When a peptide composed of the same sequence but with Ala replacing Ser994 was used as a substrate, no phosphorylation was observed, thus demonstrating the specificity of the reaction. As expected, TBK1 induced the phosphorylation of CK1tide, a substrate of casein kinase 1 that was used as a positive control. As shown in Fig. 5, phosphorylation levels of the peptide containing Ser994 were $\sim 10$ times lower than those attained with CK1tide when incorporated in the assay at the same concentration.

TNF- $\boldsymbol{\alpha}$ expression in liver As detected by western blotting, hepatic TNF- $\alpha$ levels were significantly increased
$(P<0 \cdot 01)$ in OZR when compared with LZR (Fig. 6). As shown in Fig. 6, the levels of TNF- $\alpha$ fell significantly after long-term treatment with IRB.

Study 2

Animal characteristics Table 2 summarizes the body weight, glucose, insulin, and TG circulating concentration of animals in all studies. Serum glucose, insulin and TG levels, as well as the body weights, were markedly increased in the $\mathrm{ob} / \mathrm{ob}$ mouse. Obese yellow mice also presented insulin resistance and diabetes but their phenotype was milder than that presented by the ob/ob mouse. ZDF rats were obese, and presented a marked state of hyperinsulinemia.

Degree of phosphorylation of the IR at Ser994, TBK1 protein levels and association between TBK1 in the liver of animal models of insulin resistance Compared with normal mice, ob/ob mice exhibited a significant increase in hepatic IR p-S994 levels (4.1-fold increase; $P<0 \cdot 05$; Fig. $7 \mathrm{~A}$ ). This correlated with an $8 \cdot 2$-fold increase in the association of TBK1 with the IR in liver $(P<0 \cdot 01$; Fig. $7 \mathrm{~B})$ that proceeded with no change in the amount of TBK1 total protein (Fig. 7C). By contrast, 


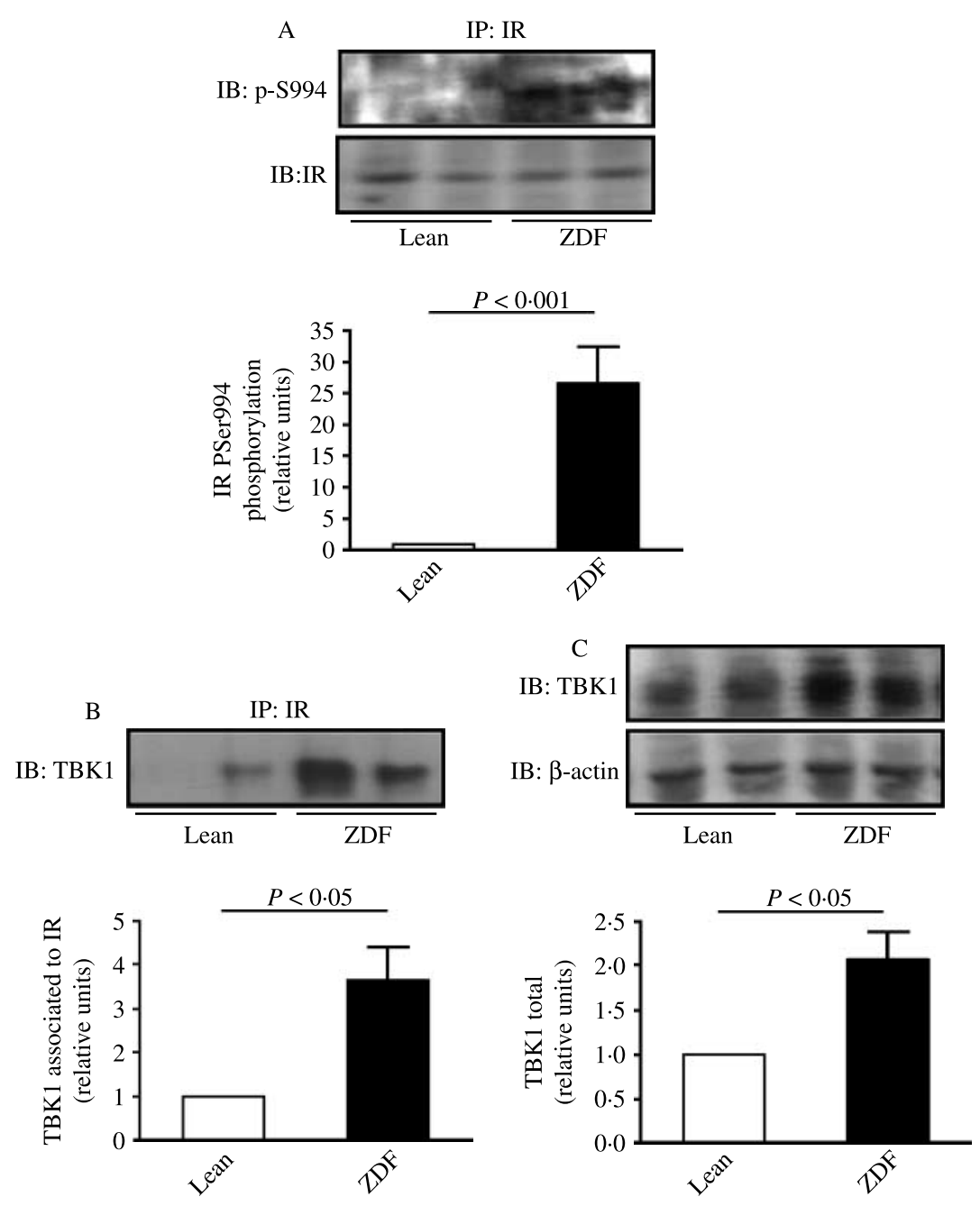

Figure 9 Degree of phosphorylation of the IR at Ser994 in liver of ZDF rats (A). Association between the IR and TBK1 (B). Hepatic TBK1 protein levels (C). Quantification of phosphorylation by scanning densitometry is given below immunoblots. Scanning data are expressed as fold increase over control values \pm S.E.M. $(n=6-7)$.

in comparison with their corresponding normal counterparts, obese yellow mice presented unaltered hepatic phosphorylation of the IR p-S994 levels or in the association of TBK1 with the IR (Fig. 8). Hyperglycemic ZDF rats displayed a very large increase in hepatic IR p-S994 levels (21-fold above lean values; $P<0 \cdot 001$; Fig. 9A). This change correlated with a $3 \cdot 6$-fold increase in the amount of TBK1 associated with the $\operatorname{IR}(P<0 \cdot 05 ;$ Fig. $9 \mathrm{~B})$ and with an increase in the amount of TBK1 $(100 \%$ increase above lean values; $P<0 \cdot 05$; Fig. 9C).

Effects of in vivo TNF- $\alpha$ infusion on hepatic IR phosphorylation and association between TBK1 and the IR Interestingly, i.v. infusion of TNF- $\alpha$ during $4 \mathrm{~h}$ originated a $78 \%$ increase in the IR p-S994 levels in liver
(Fig. 10A) and resulted in a 150\% increase in the amount of TBK1 associated with the IR (Fig. 10B). As shown in Fig. 10, TBK1 protein levels remained unaltered after TNF- $\alpha$ infusion (Fig. 10C).

\section{Discussion}

In the present study, we have shown that phosphorylation of the IR in Tyr residues that promote insulin signaling are reduced in OZRs. This reduction is linked to an increase in IR phosphorylation at Ser994. Furthermore, we provide evidence for involvement of the Ser/Thr kinase TBK1 in this mechanism of insulin resistance. Further studies performed in other models of diabetes/insulin resistance corroborated 

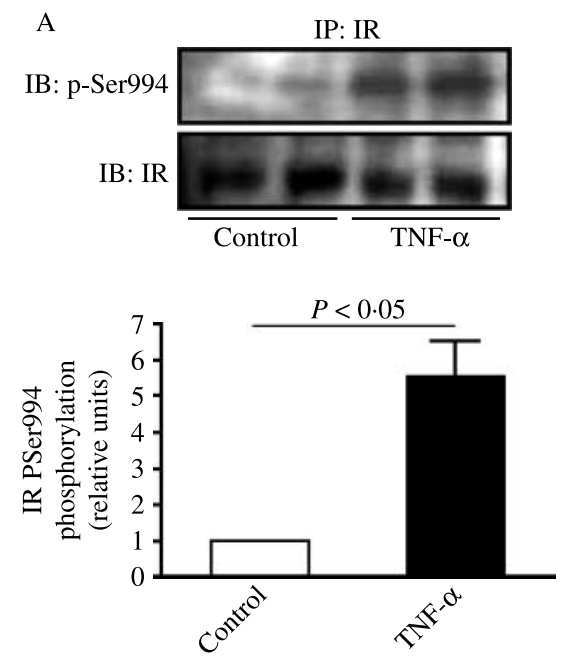

B
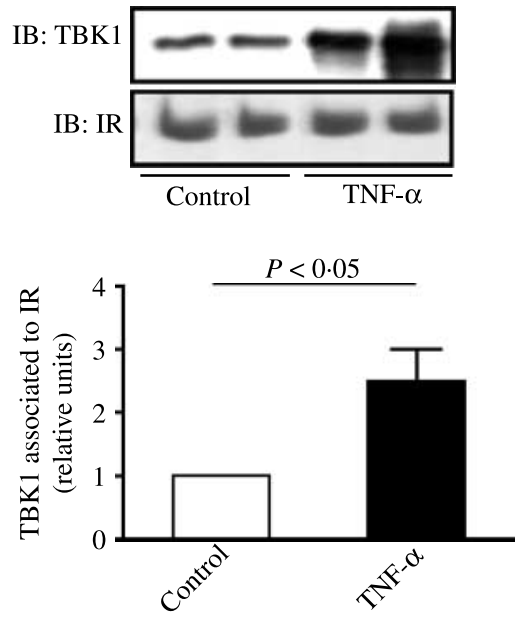

C
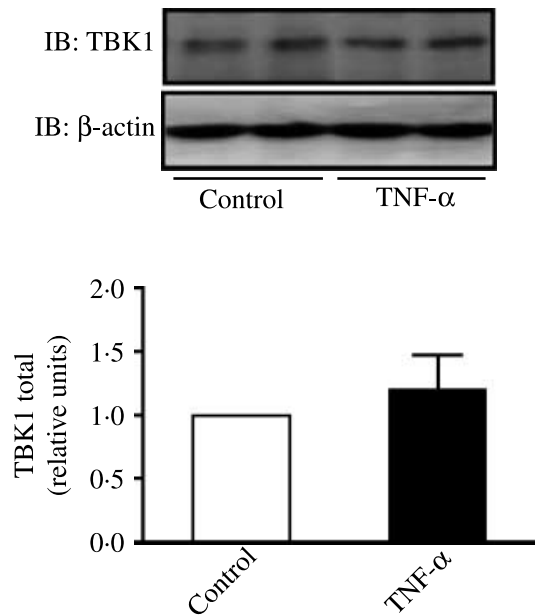

Figure 10 Degree of phosphorylation of the IR at Ser994 in liver of TNF- $\alpha$-infused rats (A). Association between the IR and TBK1 (B). Hepatic TBK1 protein levels (C). Quantification of phosphorylation by scanning densitometry is given below immunoblots. Scanning data are expressed as fold increase over control values \pm S.E.M. $(n=4)$.

the involvement of TBK1 in a mechanism of attenuation of IR function. The main data indicative of this is as follows. TBK1 was found in immunoprecipitates obtained by incubating liver homogenates with anti-IR antibodies, suggestive of an interaction between IR and TBK1 in liver. In addition, we found that the amount of TBK1 associated with the IR was much larger in immunoprecipitates obtained from the liver of OZR than in lean rats. Presumably, as a consequence of the higher hepatic TBK1 protein content found in obese rats. The molecular nature of the relationship between TBK1 and the IR has to be further investigated. Even though our results show the coexistence of the IR and TBK1 in an association complex, no inference of a direct interaction between these two proteins could be determined in our present study. Finally, using an in vitro kinase assay, we demonstrated that TBK1 can phosphorylate a peptide of the IR that includes Ser994 in vitro.

In previous reports, we showed that OZR display a dramatic increase in TNF- $\alpha$ hepatic levels, as detected by inmunohistochemistry (Toblli et al. 2008). In concurrence with those findings, in the present study, we proved that total abundance of TNF- $\alpha$ protein levels (as detected by immunoblotting) is greatly increased in these animals. AT1R blockade reduced hepatic TNF- $\alpha$ levels to lean values. Interestingly, these changes correlated with an improvement of insulin signal transduction, suggesting that the local RAS could be implicated as a player in the development of insulin resistance and type 2 diabetes.

Cross-talk between the RAS and the insulin signaling system has drawn great attention because hypertension and 
insulin resistance often coexist (Calegari et al. 2005, Velloso et al. 2006). It has been shown that Ang II infusion induces insulin resistance as well as a substantial reduction in glucose disposal in normal skeletal muscle (Rao 1994, Richey et al. 1999). Conversely, treatment with AT1R blockers enhances insulin sensitivity (Henriksen et al. 2001, Shiuchi et al. 2004, Muñoz et al. 2006). Therefore, overactivity of the RAS is likely to impair insulin signaling and contribute to insulin resistance.

Previous data from our group demonstrated that long-term selective AT1R blockade with IRB exerts its insulin sensitizing effects at least partially by improving signaling in vivo (Muñoz et al. 2006). This treatment was associated with an improvement of both hepatic insulin-stimulated phosphorylation of IR at Tyr residues that proceeded in parallel with a reduction in the phosphorylation at the inhibitory site of the IR Ser994 in OZR (Muñoz et al. 2006). In the present study, we corroborated these findings by evaluating tyrosyl phosphorylation sites critical for activation of the IR signaling cascade, including residues Tyr1158/1162/1163, located in the activation loop pf the IR kinase domain, and also by measuring the degree of phosphorylation of IR Tyr972 located in the juxtamembrane domain which participates in IRS-1 recruitment (Youngren 2007). Phosphorylation at these sites was greatly impaired in the liver of OZR and was restored after IRB treatment. Increased Ser phosphorylation of IRS-1 is a common finding in insulin resistance and type 2 diabetes and it has been the focus of attention of most studies. Several mediators such as, phorbol esters, free fatty acids, Ang II, hyperinsulinemia, and pro-inflammatory cytokines are able to induce phosphorylation of the IRS-1 through the activation of a large number of Ser/Thr protein kinases (Johnston et al. 2003), including JNK, IKK, ERK, PKC, mTOR, and S6K1 (Johnston et al. 2003). Data accumulated so far show that multiple changes in Ser/Thr and Tyr phosphorylation, in different components of the insulin signaling pathway are linked to the modulation of insulin sensitivity and generation of insulin resistance but the role of IR serine phosphorylation in these processes remains elusive. Our present results suggest that TBK1 is a kinase that participates in the negative modulation of the IR activity, thus supporting a new role for this enzyme and indicating its participation in the insulin resistance mechanism that involves phosphorylation of the IR at Ser994.

In the last decade, several works have provided strong evidence in support of a major role for inflammation in the pathogenesis of insulin resistance and type 2 diabetes (de Luca \& Olefsky 2008). Pro-inflammatory cytokines produced by adipose tissue in obesity states activate several serine kinases that disrupt the insulin signaling machinery and generate insulin resistance (Hotamisligil \& Spiegelman 1994, Shoelson et al. 2006, De Luca \& Olefsky 2008). Additionally, the existence of locally produced cytokines that attenuate insulin action was shown in rodent and humans with non-alcoholic steatohepatitis (Li et al. 2003, Tilg \& Hotamisligil 2006). For example, increased levels of TNF- $\alpha$, IL-1, and -6 have been reported in numerous diabetic and insulin resistant states
(Hotamisligil \& Spiegelman 1994, Klover et al. 2003, Jager et al. 2007).

TBK1 is a Ser/Thr kinase implicated in the regulation of NF- $\kappa B$ activity (Pomerantz \& Baltimore 1999). Known kinases that are homologous to TBK1 are IKK- $\alpha$ and IKK- $\beta$, which are each $27 \%$ identical and $45 \%$ similar in the region between TBK1 residues 9 and 353 (Pomerantz \& Baltimore 1999). This protein is expressed in various rodent tissues such as stomach, small intestine, lung, testis, skin, brain, heart, kidney, spleen, thymus, and liver (Pomerantz \& Baltimore 1999) and appears to be activated by phorbol esters, tumor promoters and growth factors (Tojima et al. 2000). The known functions of TBK1 are related with the development of the innate antiviral response (Harris et al. 2006) and with tumor angiogenesis (Korherr et al. 2006). In the present report, we confirmed that TNF- $\alpha$ is directly associated with the induction of TBK1 in liver, first by showing that in OZRs large hepatic TBK1 levels coexist with increased levels of TNF- $\alpha$ and second by showing that rats infused by $4 \mathrm{~h}$ with TNF- $\alpha$ displayed large levels of association of this enzyme with the IR. Additionally, we provided expression data of TBK1 from other diabetic/insulin resistant animal models, thus reinforcing the suggestion that TBK1 might negatively regulate insuling signaling through a mechanism related with the Ser994 phosphorylation of the IR, placing the inhibition of this kinase as a promising target for the treatment of type 2 diabetes and related disorders. Together with our previous report showing the participation of members of the PKC family in the phosphorylation of IR Ser994, the present results underscore the importance of Ser994 as an IR phosphorylation site that integrates inflammation/obesity signals through PKC and TBK1 to create a state of insulin resistance.

\section{Declaration of interest}

The authors declare that there is no conflict of interest that could be perceived as prejudicing the impartiality of the research reported.

\section{Funding}

F P D, J E T and D T are Career Investigators from Consejo Nacional de Investigaciones Científicas y Tecnológicas of Argentina (CONICET), and received grant support from Agencia Nacional de Promoción Científica y Tecnológica of Argentina, CONICET and the University of Buenos Aires (UBA). J F G is a research fellow from UBA, M C M and M A M are research fellows from CONICET.

\section{References}

Arkan MC, Hevener AL, Greten FR, Maeda S, Li ZW, Long JM, Wynshaw-Boris A, Poli G, Olefsky J \& Karin M 2005 IKK-beta links inflammation to obesity-induced insulin resistance. Nature Medicine 11 191-198. Bollag GE, Roth RA, Beaudoin J, Mochly-Rosen D \& Koshland DE Jr 1986 Protein kinase $\mathrm{C}$ directly phosphorylates the insulin receptor in vitro and reduces its protein kinase activity. PNAS 83 5822-5824. 
Cai D, Yuan M, Frantz DF, Melendez PA, Hansen L, Lee J \& Shoelson SE 2005 Local and systemic insulin resistance resulting from hepatic activation of IKK-beta and NF-kappaB. Nature Medicine 11 183-190.

Calegari VC, Alves M, Picardi PK, Inoue RY, Franchini KG, Saad MJ \& Velloso LA 2005 Suppressor of cytokine signaling-3 provides a novel interface in the cross-talk between angiotensin II and insulin signaling systems. Endocrinology 146 579-588.

Coba MP, Turyn D \& Peña C 2003 Synthesis and immunogenic properties of phosphopeptides related to the human insulin receptor. Journal of Peptide Research 61 17-23.

Coba MP, Muñoz MC, Dominici FP, Toblli JE, Peña C, Bartke A \& Turyn D 2004 Increased in vivo phosphorylation of insulin receptor at serine 994 in the liver of obese insulin-resistant Zucker rats. Journal of Endocrinology 182 433-444.

Considine RV, Nyce MR, Allen LE, Morales LM, Triester S, Serrano J, Colberg J, Lanza-Jacoby S \& Caro JF 1995 Protein kinase C is increased in the liver of humans and rats with non-insulin-dependent diabetes mellitus: an alteration not due to hyperglycemia. Journal of Clinical Investigation 95 2938-2944.

Dohi Y, Criscione L, Pfeiffer K \& Luscher TF 1994 Angiotensin blockade or calcium antagonists improve endothelial dysfunction in hypertension: studies in perfused mesenteric resistance arteries. Journal of Cardiovascular Pharmacology 24 372-379.

Folli F, Kahn CR, Hansen H, Bouchie JL \& Feener EP 1997 Angiotensin II inhibits insulin signaling in aortic smooth muscle cells at multiple levels. A potential role for serine phosphorylation in insulin/angiotensin II crosstalk. Journal of Clinical Investigation 100 2158-2169.

Häring HU, Kasuga M, White MF, Crettaz M \& Kahn CR 1984 Phosphorylation and dephosphorylation of the insulin receptor: evidence against an intrinsic phosphatase activity. Biochemistry 23 3298-3306

Harris J, Olière S, Sharma S, Sun Q, Lin R, Hiscott J \& Grandvaux N 2006 Nuclear accumulation of $\mathrm{cRel}$ following C-terminal phosphorylation by TBK1/IKKe. Journal of Immunology 177 2527-2535.

Henriksen EJ, Jacob S, Kinnick TR, Teachey MK \& Krekler M 2001 Selective angiotensin II receptor receptor antagonism reduces insulin resistance in obese Zucker rats. Hypertension 38 884-890.

Hotamisligil GS \& Spiegelman BM 1994 Tumor necrosis factor alpha: a key component of the obesity-diabetes link. Diabetes 43 1271-1278.

Itani SI, Zhou Q, Pories WJ, MacDonald KG \& Dohm GL 2000 Involvement of protein kinase $\mathrm{C}$ in human skeletal muscle insulin resistance and obesity. Diabetes 49 1353-1358.

Jager J, Grémeaux T, Cormont M, Le Marchand-Brustel Y \& Tanti J-F 2007 Interleukin- $1 \beta$-induced insulin resistance in adipocytes through down regulation of insulin receptor substrate-1 expression. Endocrinology 148 241-251.

Jandeleit-Dahm KA, Tikellis C, Reid CM, Johnston CI \& Cooper ME 2005 Why blockade of the renin-angiotensin system reduces the incidence of new-onset diabetes. Journal of Hypertension 23 463-473.

Johnston AM, Pirola L \& Van Obberghen E 2003 Molecular mechanisms of insulin receptor substrate protein-mediated modulation of insulin signaling. FEBS Letters 546 32-36.

Kasuga M, Zick Y, Blith DL, Karlsson FA, Häring HU \& Kahn CR 1982 Insulin stimulation of phosphorylation of the beta subunit of the insulin receptor. Formation of both phosphoserine and phosphotyrosine. Journal of Biological Chemistry 257 9891-9894.

Kern PA, Ranganathan S, Li CH, Wood L \& Ranganathan G 2001 Adipose tissue tumor necrosis factor and interleukin-6 expression in human obesity and insulin resistance. American Journal of Physiology. Endocrinology and Metabolism 280 E745-E751.

Klover PJ, Zimmers TA, Koniaris LG \& Mooney RA 2003 Chronic exposure to interleukin-6 causes hepatic insulin resistance in mice. Diabetes $\mathbf{5 2}$ 2784-2789

Korherr C, Gille H, Schäfer R, Koenig-Hoffmann K, Dixelius J, Egland KA, Pastan I \& Brinkmann U 2006 Identification of proangiogenic genes and athways by high-throughput functional genomics: TBK1 and the IRF3 pathway. PNAS 103 4240-4245.
Li M, Youngren JF, Dunaif A, Goldfine ID, Maddux BA, Zhang BB \& Evans JL 2002 Decreased insulin receptor (IR) autophosphorylation in fibroblasts from patients with PCOS: effects of serine kinase inhibitors and IR activators. Journal of Clinical Endocrinology and Metabolism 87 4088-4093.

Li Z, Yang S, Lin H, Huang J, Watkins PA, Moser AB, Desimone C, Song XY \& Diehl AM 2003 Probiotics and antibodies to TNF inhibit inflammatory activity and improve nonalcoholic fatty liver disease. Hepatology 37 343-350.

de Luca C \& Olefsky JM 2008 Inflammation and insulin resistance. FEBS Letters $\mathbf{5 8 2} 97-105$.

Muñoz MC, Argentino DP, Dominici FP, Turyn D \& Toblli JE 2006 Irbesartan restores the in vivo insulin signaling pathway leading to Akt activation in obese Zucker rats. Journal of Hypertension 24 1607-1617.

O'Donnell MP, Cray GS, Oda H, Kasiske BL, Powell JR \& Keane WF 1997 Irbesartan lowers blood pressure and ameliorates renal injury in experimental non-insulin-dependent diabetes mellitus. Kidney International 63 S218-S220.

Pickup JC \& Crook MA 1998 Is type II diabetes mellitus a disease of the innate immune system? Diabetologia 41 1241-1248.

Pillay TS, Whittaker J, Lammers R, Ullrich A \& Siddle K 1991 Multisite serine phosphorylation of the insulin and IGF-1 receptors in transfected cells. FEBS Letters 288 206-211.

Pomerantz JL \& Baltimore D 1999 NF kappaB activation by a signaling complex containing TRAF2, TANK and TBK1, a novel IKK-related kinase. EMBO Journal 18 6694-6704.

Pradhan AD, Manson JE, Rifai N, Buring JE \& Ridker PM 2001 C-reactive protein, interleukin 6 , and risk of developing type 2 diabetes mellitus. Journal of the American Medical Association 286 327-334.

Qin B, Anderson RA \& Adeli K 2008 Tumor necrosis factor- $\alpha$ directly stimulates the overproduction of hepatic apolipoprotein B100-containing VLDL via impairment of hepatic insulin signaling. American Journal of Physiology. Gastrointestinal and Liver Physiology 294 G1120-G1129.

Qu X, Seale JP \& Donnelly R 1999 Tissue and isoform-selective activation of protein kinase $\mathrm{C}$ in insulin resistant obese Zucker rats - effects of feeding. Journal of Endocrinology 162 207-214.

Rao RH 1994 Effects of angiotensin II on insulin sensitivity and fasting glucose metabolism in rats. American Journal of Hypertension 7 655-660.

Richey JM, Ader M, Moore D \& Bergman RN 1999 Angiotensin II induces insulin resistance independent of changes in interstitial insulin. American Journal of Physiology. Endocrinology and Metabolism 277 E920-E926.

Shiuchi T, Iwai M, Li HS, Wu L, Min LJ, Li JM, Okumura M, Cui T-X \& Horiuchi M 2004 Angiotensin II type-1 receptor blocker valsartan enhances insulin sensitivity in skeletal muscles of diabetic mice. Hypertension 43 1003-1110.

Shoelson SE, Lee J \& Goldfine AB 2006 Inflammation and insulin resistance. Journal of Clinical Investigation 116 1793-1801.

Stadtmauer L \& Rosen OM 1986 Increasing the cAMP content of IM-9 cells alters the phosphorylation state and protein kinase activity of the insulin receptor. Journal of Biological Chemistry 261 3402-3407.

Strack V, Stoyanov B, Bossenmaier B, Mosthaf L, Kellerer M \& Haring HU 1997 Impact of mutations at different serine residues on the tyrosine kinase activity of the insulin receptor. Biochemical and Biophysical Research Communications 239 235-239.

Strack V, Hennige AM, Krützfeldt J, Bossenmaier B, Klein HH, Kellerer M, Lammers R \& Haring HU 2000 Serine residues 994 and 1023/25 are important for insulin receptor kinase inhibition by protein kinase $\mathrm{C}$ isoforms beta2 and theta. Diabetologia 43 443-4493.

Takayama S, White MF \& Kahn CR 1988 Phorbol ester-induced serine phosphorylation of the insulin receptor decreases its tyrosine kinase activity. Journal of Biological Chemistry 263 3440-3447.

Taniguchi CM, Emanuelli B \& Kahn CR 2006 Critical nodes in signalling pathways: insights into insulin action. Nature Reviews Molecular Cell Biology 7 85-96.

Tilg H \& Hotamisligil GS 2006 Nonalcoholic fatty liver disease: cytokineadipokine interplay and regulation of insulin resistance. Gastroenterology 131 934-945.

Toblli JE, Muñoz MC, Cao G, Mella J, Pereyra L \& Mastai R 2008 ACE inhibition and AT1 receptor blockade prevent fatty liver and fibrosis in obese Zucker rats. Obesity 16 770-776. 
Tojima Y, Fujimoto A, Delhase M, Chen Y, Hatakeyama S, Nakayama K, Kaneko Y, Nimura Y, Motoyama N, Ikeda K et al. 2000 NAK is an IkappaB kinase-activating kinase. Nature 404 778-782.

Velloso LA, Folli F, Perego L \& Saad MJ 2006 The multi-faceted cross-talk between the insulin and angiotensin II signaling systems. Diabetes/Metabolism Research and Reviews 22 98-107.

White MF \& Kahn CR 1994 The insulin signalling system. Journal of Biological Chemistry 269 1-4.

Youngren JF 2007 Regulation of insulin receptor. Cellular and Molecular Life Sciences 64 873-891.
Yuan M, Konstantopoulos N, Lee J, Hansen L, Li ZW, Karim M \& Shoelson SE 2001 Reversal of obesity-and diet- induced insulin resistance with salicylates or targeted disruption of Ikkbeta. Science 293 1673-1677.

Received in final form 9 February 2009

Accepted 20 February 2009

Made available online as an Accepted Preprint 24 February 2009 